\title{
DETERMINATION OF EFFICIENCY OF INVESTMENTS IN CONSTRUCTION
}

\author{
Leonas USTINOVICHIUS \\ Department of Building Technology and Management, Vilnius Gediminas Technical University, \\ Sauletekio al. 11, LT-10223 Vilnius, Lithuania \\ E-mail: leonasu@st.vtu.lt
}

Received 2 December 2003; accepted 4 March 2004

\begin{abstract}
Decision making is associated with ranking problems aimed to obtain a set of preference order of solutions. People can make mistakes choosing the best object for investments. Due to high cost of such mistakes, such a choice should be well founded. A major goal of paper is to develop a theoretical basis for creating a decision support system aimed to increase building construction and reconstruction investment efficiency by applying multiattribute decision making approaches and mathematical modelling. To achieve the goal, the following problems have to be solved: to analyse new models currently used in developing investment strategies in building construction and reconstruction, to make a classification of construction investment projects and to describe the stages of determining the efficiency of construction investments, to create a family of multiattribute decision methods to be used in the analysis of investment projects in building construction and reconstruction, to create multiple attribute decision support system based on the multiattribute methods developed for determining the efficiency of construction and reconstruction investment projects.
\end{abstract}

KEYWORDS: Building construction and reconstruction; Investment efficiency; Decision-making problems; Multiattribute decision methods; Multiple attribute decision support system

\section{INTRODUCTION}

The problem of construction investment is of paramount importance, because the investments determine the potential of construction and the structure of expenses. The successful performance of the company is also closely associated with the investment policy since the latter embraces the expenses required as well as considerable financial resources. Efficient planning and management of investments have become not only an important but also a complicated problem in the dynamically changing environment.

The calculation of investments is an expensive tool of enterprise management in planning the investments. It can be perceived as the harmonization and evaluation of the mod- els for investment decision - making. Therefore, in calculating investments, beside the methods and models based on the data obtained in the study of income and expenses, the multiple attribute decision support methods assessing the efficiency are applied.

Evaluation of variants efficiency when there is only one objective function. Static models (Perridon, Steiner, 1999). Only one period is being analysed while applying a static model. It is a particular period of exploitation that should be considered as an essential period of exploitation, or, in hypothetical terms, it is a medium period. In such a case, all the data from the planned period are received, which characterize the relative medium period.

Comparative costs calculation (Huch, 1986; Kilger, 1986; Weber, 1991). Costs are the ob- 
jective function of the costs comparison models. Because investments are long - term, the expenditures taken into account are also of long lasting character.

The question arises if it is justified to rely on one objective function or it is possible to ignore relations between other areas of enterprise activities in the process of decision making. Moreover, the problem of static model should be assessed critically (Blohm, Lüder, 1991).

Comparative Profit Accounting (Kern, 1976). While performing comparative profit accounting, it is possible to assess both absolute and relative benefits.

Static Depreciation Deduction (Perridon, Steiner, 1999; Kern, 1976). The objective function of depreciation deduction is the time of depreciation or recovery of the investment project. For statistical depreciation deduction, the same conclusions are valid as for other statistical methods and models of investment calculation. It should be noted, that summarizing the effects of depreciation, the above calculations should not to be considered the only criterion for investment decision making.

Dynamic models (Heinhold, 1997; Nemec et al., 1990). Investment projects are described by instalments and payoffs, which should be paid while realizing the projects in the particular period of time. The assumption is usually related with this, that major influence of alter- natives is limited by definite specified instalments and payoffs. Their values can be determined in terms of time intervals. Instalments and payoffs accounting as well as the analysis of dynamic indices in the particular periods is an essential feature differentiating the dynamic models from the statistical ones.

The survey of dynamic models for the evaluation of utility is presented in the diagram below (Figure 1).

It should be noted, that the dynamic evaluation of utility model in comparison with the static model is closer to reality, because, in this case, several periods are analysed. Therefore, even though the application of the dynamic model requires more time, it is more efficient compared with the static model.

Many assumptions exist in the dynamic model (i.e. is the only objective function, exploitation period and data reliability determined, as well as payments adequacy at a certain period of time, the existence of developed capital market, etc.) that are to be checked.

Evaluation of the efficiency of investment projects with a number of objective functions. In solving the investment problems, the decision maker (DM) has several aims (Vetschera, 1991; Fandel, 1979). This primarily applies to strategic investment, which is based on the sophisticated systems of evaluation (Riedel, 1989). The utility analysis is a relatively simple decision making technique based

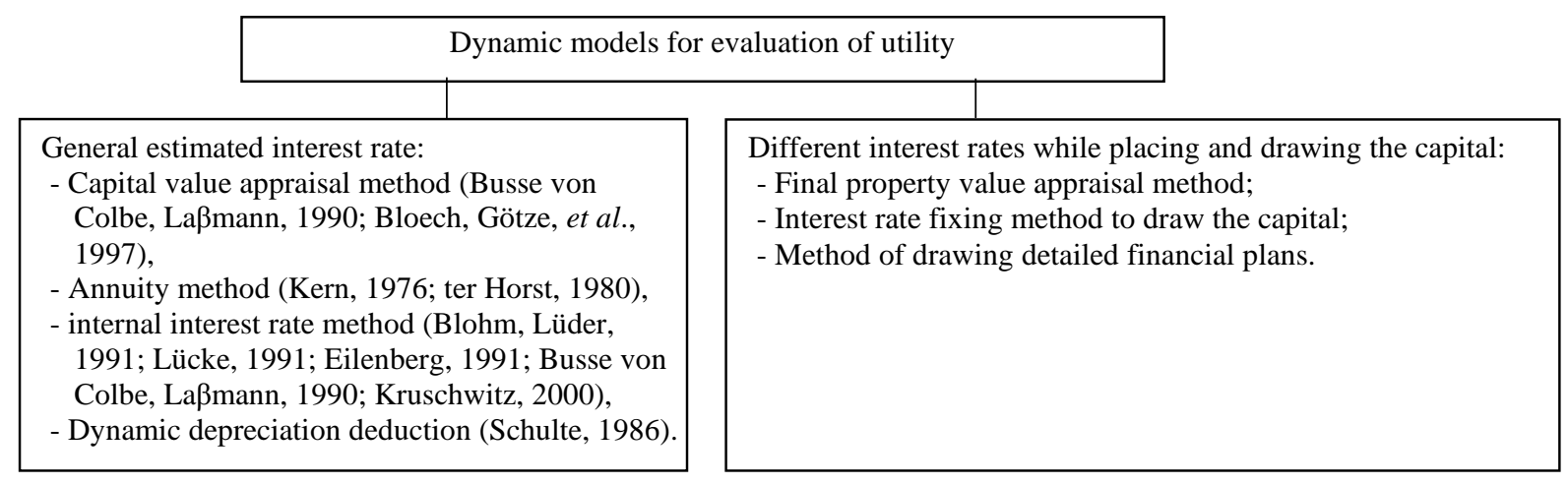

Figure 1. Dynamic models for evaluation of utility 
on simple calculations for solving multicriteria problems (Vetschera, 1991; Fandel, 1979).

One of the possible approaches is based on classification made according to the type of information received from the decision maker (Larichev, Kochin et al., 2002). It includes:

1. Methods based on quantitative measurements. This group consists of widely known methods within multicriteria utility theory (Keeney, Raiffa, 1976; Hwang, Yoon, 1981; Triantaphyllou, 2000) and some new methods.

2. Methods based on initial qualitative assessments, the results of which later take a quantitative form. This group consists of analytic hierarchy method (Saaty, 1994), as well as the methods based on undefined sets (Zadeh, 1978).

3. Methods based on quantitative measurements but using a few indices to compare the alternatives (comparison preference method). This group consists of comparison preference methods (Roy, 1996).

4. Methods based on qualitative data not using a shift to quantitative variables. This group comprises verbal decision analysis (VDA) methods (Larichev, Olson, 2001).

It is possible to use methods from different groups of the classification above to analyze the effectiveness of investment policies. However, one should take into account peculiarities of individual investment problems.

When criteria are mostly quantitative and sufficiently precise, quantitative methods are perfectly applicable. For qualitative criteria one can use Saati scale to represent them quantitatively. However, in this case variability intervals for values of quantitative and qualitative criteria differ enormously. The variety interval for Saati's nine-interval scale is usually in the range of $600-700 \%$, but quantitative variety intervals for the problems considered are about $10-90 \%$. This often results in the strong influence of minor criteria over the final conclusion. According to the mathematical algorithms for the methods of the first group criteria with wider variety intervals have more influence on the result.
To avoid the difficulties above VDA methods or comparative preference methods (the third group) could be used. Comparative preference methods demonstrate good results, when using threshold systems for criteria description. However, the process is rather complicated and requires a trained specialist. Therefore, the only opportunity we often have is to use the VDA methods.

Though the methods of the second group can also be applied to investment problem analysis, they are high-sensitive to subjectivity in criteria values (e.g., what an expert evaluates as 4 , the others can evaluate as 6 and so on). Besides, contradictory answers are possible, which could lead to cycles. At the same time VDA methods have a set of procedures to check DM answers for contradictions.

VDA methods also show good results when uncertainty arises (e.g., imprecise values of criteria or failure to evaluate the importance of criteria).

One of the first VDA methods for choosing the best alternative out of a group of given multicriteria alternatives by pair-wise comparisons was the method PARK (Larichev, Moshkovich, 1997), which was applied to solution of a number of important practical problems (Larichev, Brown, 2000).

However, the method PARK has serious disadvantages:

- It is applicable for a choice out of 3-5 alternatives only, because the method uses pair-wise comparisons of all variants;

- Criteria scales have only verbal estimations;

- The assumptions on possible allowed operations for DM information elicitation were not supported by the results of psychological research.

A major goal of research is to develop a theoretical basis for creating a decision support system aimed to increase building construction and reconstruction investment efficiency by applying multiattribute decision making approaches and mathematical modelling. 


\section{CLASSIFICATION OF CONSTRUCTION INVESTMENT PROJECTS}

According to the methods of investment analysis as well as efficiency criteria, the investment projects can be divided into these subgroups: agricultural buildings, old town buildings, dwelling houses and industrial buildings (Figure 2).

In solving the problem, it is possible to apply the particular methods to any subgroup. Obviously, the assessment criteria for construction investment should also be determined with account of the types of buildings.

Classification of Problems for Determining Construction Investment Efficiency. Construction investment efficiency may be determined by solving a number of problems and applying decision methods (French et al., 1997; Jones, 1990; Brown, 1991). First, the most efficient site for new construction should be selected and the efficiency of the site for the buildings to be repaired should be determined. Then the investment projects have to be analysed by multicriteria methods. According to the project selected, a building is designed on the basis of the effective architectural and constructional decisions made.

It is very important to establish the financing schemes, because very often a final success of investment depends on this stage. In some projects, the method of financing determines the efficiency of the investment project as a whole.

In fact, all the investors consider the prob- lem of project reliability. They discuss the dilemma whether to select the most profitable investment project or the most reliable one. Very often risk factors determine the efficiency of the project.

Classification of Investment Financing Schemes. The main financing schemes may be divided into those relying on the owner's capital, capital of investors' enterprise, loans, leasing, investment subsidy, foreign investments and international investments (Behrens, Hawranek, 1991; Ghasemzadeh, Archer, 2000; Makridakis et al., 1983). Usually, loans are used very effectively for construction investments and can raise the overall efficiency of the investment project. So, are basically considered Mortgage Loans (Friedman, Ordway, 1997; Lumby, 1994), Mortgage Loans with Invariable Interest Rate, Mortgage Loans with Variable Interest Rate, Wrap Mortgage, Real Estate Financing through Instalment Sale, Participiation Mortgage Loans, Real Estate Financing while Establishing Joint Ventures (Tarasevich, 2000), Construction Mortgage Loans (Friedman, Ordway, 1997), Land Reclaim Mortgage Loan, Real Estate for Rent Financing, Financing Real Estate through Investors' Consortium, Rural Building Financing (Lunkevichius, Ustinovichius et al., 2001).

\section{QUANTITATIVE MULTICRITERIA APPROACH MKDM1}

Methods based on a single criterion can hardly be used in solving the problems associ-

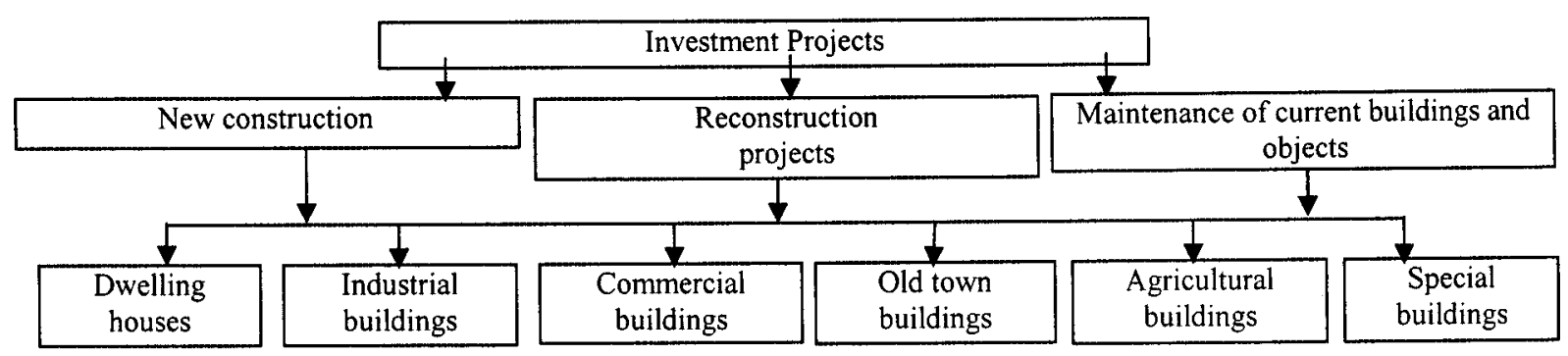

Figure 2. Classification of investment projects 
ated with sophisticated technological or marketing systems. It is multiple attribute decision system, taking into account major efficiency criteria, that enables the effective methods of solving complicated problems to be developed.

A description of some multiattribute decision methods (MADM) can be found in literature. However, the application of one of these methods is not sufficient. Various methods can be combined, grouped or applied in turn. A set of multiattribute decision methods (multicriteria approach) suggested is given in Figure 3 .

First, the applicable variants of technological and economic projects are developed. Then the criteria of efficiency (attributes) to be used in analysing the variants are established. Based on the judgements of experts, the weights of the criteria are determined, and the concordance of expert judgements is checked. If the judgements are in concordance, the efficiency values obtained can be relied upon. To avoid accidental errors, three methods of determining the variant utility function should be used, i.e. similarity to ideal solution (TOPSIS), simple additive weighting (SAW) and LINMAP.

Pairwise comparison for determining the weights of the efficiency criteria. Decision making system may help to determine the weights of the attributes developed (Ustinovichius, Jakuchionis, 2000). This may be achieved by pairwise comparison expertise method suggested by T. Saaty (Saaty, 1994).

Pairwise comparison is an advanced method, because experts may compare the attributes in pairs, which is important when the latter are many. Pairwise evaluation may be considered sufficiently reliable only if the judgements of experts are in concordance. Therefore, when statistically processing the data obtained from the experts, the index of concordance should be determined and the causes of discordance identified. Pairwise actions method does not provide for expert judgements concordance analysis, therefore, an expert evaluation method (Zavadskas et al., 1995) supplemented with concordance checking procedure suggested by L. Evlanov may be applied (Evlanov, 1984).

\section{Methods of determining objective and} integrated weights of attributes. In various papers, the attributes are subdivided into objective and subjective. The attribute weight is obtained based on priviledged data and vector technique (Saaty, 1994), least squares comparison (Chu et al., 1979), Delphi (Hwang, Lin, 1987), LINMAP (Linear Programming Techniques for Multidimensional Analysis of Priviledged) (Srinivasan, Shocker, 1973) and various computer - aided mathematical models (Pekelman, Sen, 1974). The latter technique uses mathematical models for obtaining the weight without priviledged data, involving entropy approach (Hwang, Yoon, 1981) and multiattribute programming methods (Fan, 1994).

Subjective and objective approaches have a number of advantages and disadvantages. The weights obtained by a subjective approach reflect subjective judgements of a person resulting in ranking of the alternatives of the particular problem. Later they acquire less rigorous values. Objective weights are obtained by mathematical methods based on subjective information. As one can see, no one of the approaches is perfect. It may be suggested that an integrated approach could be most appropriate for determining the weights of the attributes. Currently, a number of papers aimed to combine subjective and objective approaches to solve MADM problems have been published (Cook, Kress, 1994; Liang, Wang, 1994; Yan, Singh, 1994). However, the models considered present some difficulties for application. The authors themselves admit that integrated methods based on subjective and objective information are far from being perfect, as well as requiring further analysis.

Integrated, subjective and objective weights of the attributes. An objective weight of the attribute can be easily obtained by an entropy method. Assume that $S=\left\{S_{1}\right.$, $\left.S_{2}, \ldots, S_{\mathrm{m}}\right\}$ is a discrete set of alternatives. $R=\left\{R_{1}, R_{2}, \ldots, R_{n}\right\}-$ a set of attributes, and 


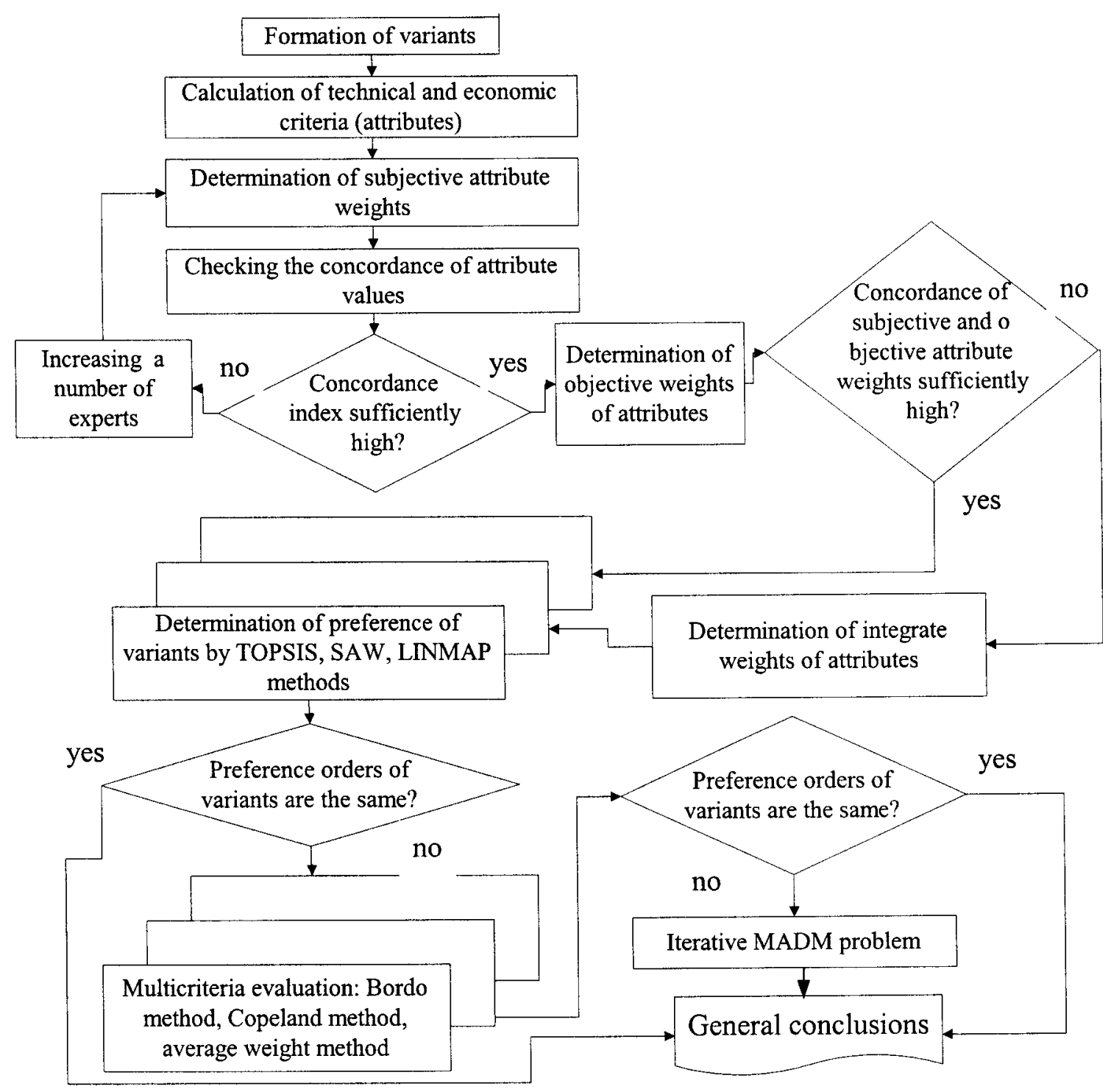

Figure 3. A family of multiattribute decision methods 
$X=\left\lfloor x_{i j}\right\rfloor_{m \times n}-$ a decision matrix, where $x_{i j}$ is $R_{j}$ attribute value of variant $S_{i}(i=1,2, \ldots, \mathrm{m} ; j$ $=1,2, \ldots, n$ ). For the sake of uniformity of measurement, it is assumed that all the initial weights in the matrix are in the range from 0 to 1 .

The value of the objective weights of the attribute is determined by the attribute dominance level. Subjective weight values show the relevance of the attribute to the variants considered. In some cases, $\overline{q_{j}}$ (subjective weight) and $q_{j}$ (objective weight) are essentially different, thereby considerably decreasing the accuracy of preference ordering of the variants. This may be accounted for the fact that minor factors can have a great influence on ranking the variants, and vice versa. Therefore, the author suggests that the formula for determining the objective weight of the attribute by entropy approach be interpreted differently in this way:

$$
\overline{q_{j}}=\frac{q_{j}^{*} q_{j}}{\sum_{j=1}^{n} q_{j}^{*} q_{j}}, \quad(j=\overline{1, n}) .
$$

To obtain the integrated weight of attribute $q^{*}$, a system of equations given below should be solved (Ustinovichius, 2001a):

$$
\left\{\begin{array}{l}
q_{1}^{*}\left(\overline{q_{1}} q_{1}-q_{1}\right)+q_{2}^{*} \overline{q_{1}} q_{2}+q_{3}^{*} \overline{q_{1}} q_{3}+\ldots+q_{n}^{*} \overline{q_{1}} q_{n}+f=0 \\
q_{1}^{* \overline{q_{2}}} q_{1}+q_{2}^{*}\left(\overline{q_{2}} q_{2}-q_{2}\right)+q_{3}^{*} \overline{q_{2}} q_{3}+\ldots+q_{n}^{*} \frac{q_{2}}{q_{n}}+f=0 \\
q_{1}^{*} \overline{q_{3}} q_{1}+q_{2}^{*} \overline{q_{3}} q_{2}+q_{3}^{*}\left(\overline{q_{3}} q_{3}-q_{3}\right)+\ldots+q_{n}^{*} q_{3} q_{n}+f=0 \\
\ldots \ldots \\
q_{1}^{*} \overline{q_{n}} q_{1}+q_{2}^{*} \overline{q_{n}} q_{2}+q_{3}^{*} \overline{q_{n}} q_{3}+\ldots+q_{n}^{*}\left(\overline{q_{n}} q_{n}-q_{n}\right)+f=0 \\
q_{1}^{*}+q_{2}^{*}+q_{3}^{*}+\ldots+q_{n}^{*}=1 .
\end{array}\right.
$$

where: $f$ is the error coefficient of the system of equations.

Later the weight $q_{j}^{*}$ will be used in multiattribute decision methods such as TOPSIS (Hwang, Yoon, 1981; Arditi, Gunaydin, 1998), SAW (MacCrimmon, 1968), LINMAP (Srinivasan, Shocker, 1973; Hwang, Yoon, 1981), etc.

Multiple criteria evaluation by the
Borda, the Copeland and the average weight methods. The availability of several research methods raises the problem of the proper choice. The question "Which method is most suitable to solve the problem?" is most important, but it is difficult to answer it. It is more difficult to assess the quality of multicriteria techniques applied to a limited number of variants mathematically described in a discrete way than that of mathematical finite element analysis. Since any of multicriteria methods has its advantages and disadvantages, there is actually no answer to the above question.

In addition, the application of various methods of calculation may yield different results (preference order). A model for assessing multiple criteria techniques is based on the Borda, the Copeland and the average weight methods.

Multicriteria decision iterative problem. When the Borda, the Copeland and the average weight methods have been applied to the analysis of variants, the uncertainty may remain on which of the alternatives is the best. The author of the present investigation suggests the multicriteria iterative decision method (Ustinovichius, 2001b) (Figure 4) to be used.

\section{DETERIMINING THE EFFICIENCY OF THE INVESTMENT PROJECT AT THE PARTICULAR STAGES}

The evaluation of siting strategies of commercial buildings. Siting strategy is very important, especially for commercial buildings. The site for such buildings should be chosen so that it could be used most advantageously. The efficient siting strategy may be described in terms of benefits divided into two groups: 1) general benefits; 2) specific benefits (the site is suitable for a particular commerce).

Making investments in real estate, a system of major attributes should be developed, which could be used as a basis for choosing the site (Figure 5). The comprehensive data on the potential site should be collected. For this purpose, geographical information systems GIS, providing all the necessary geographical 


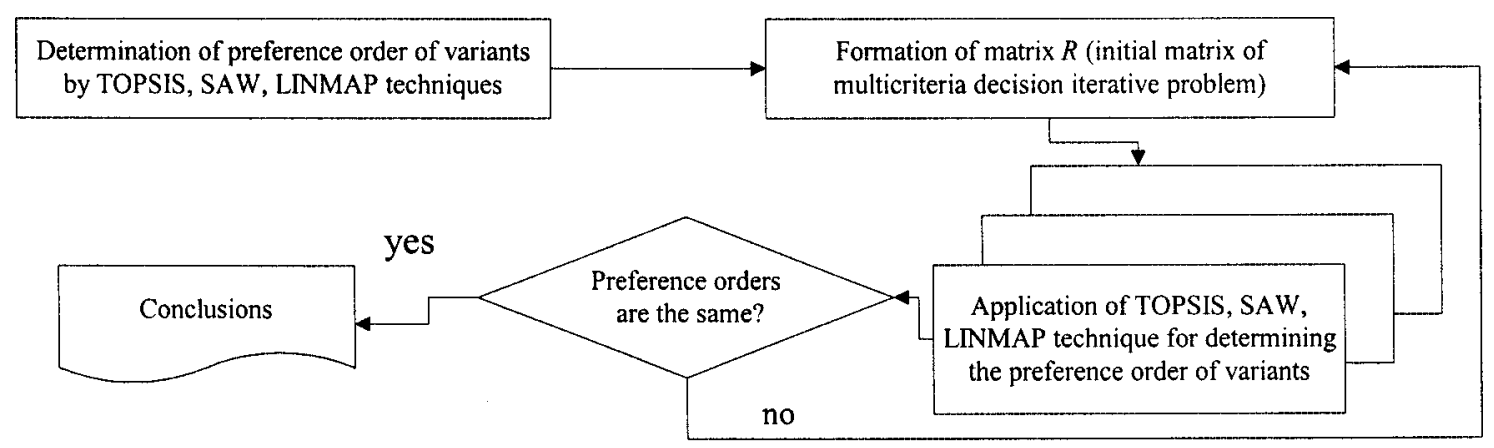

Figure 4. General structural scheme of iterative multicriteria decision analysis

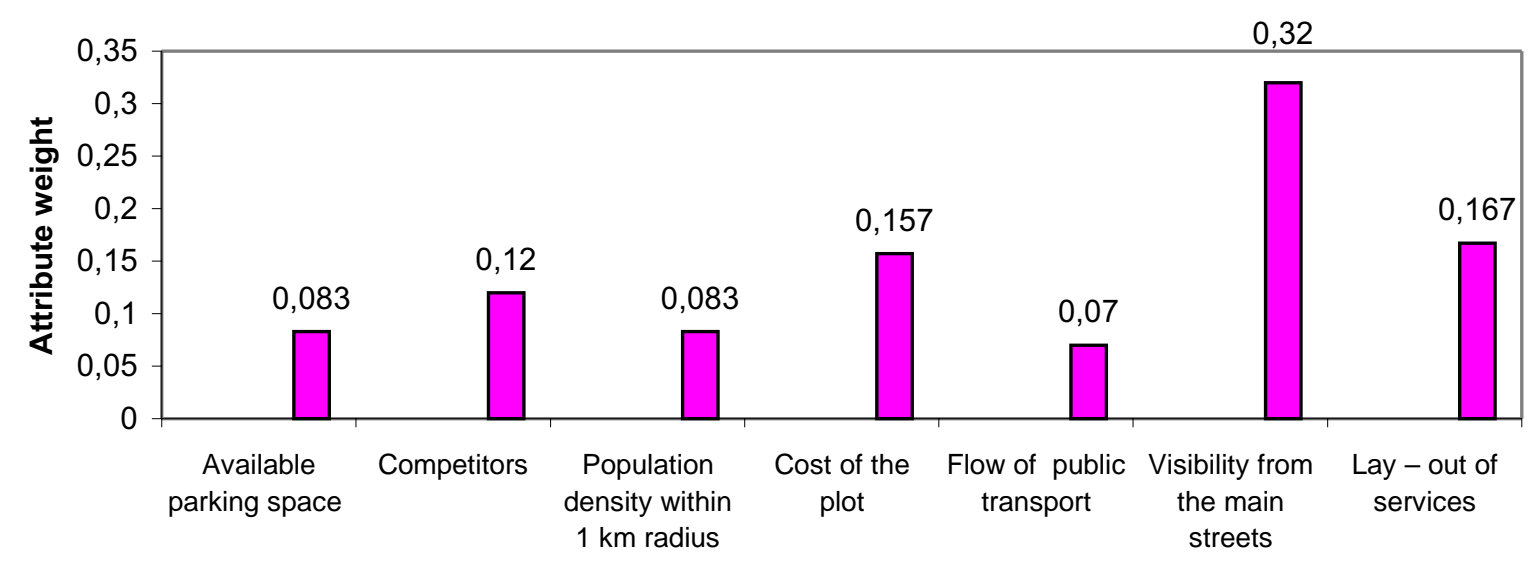

Atributes

Figure 5. Weights of attributes used in siting strategy of commercial buildings

information about the site, should be used. Based on this data, the values and weights of the attribute can be obtained (Environmental Systems Research Institute, 2001; Ustinovichius, Stasiulionis, 2001).

In practice, it is difficult to define the site as ideal as well as being the case when some attributes can be compensated by others or to associate it with a single attribute of efficiency, because any site is unique. Therefore, the above problem can be solved by applying ELECTRE III as one of the most suitable multicriteria techniques based on pairwise com- parison of variants, enabling us to learn whether the attributes of the variant allow it to become dominant.

The method referred to as ELECTRE III is a technique of selecting a set of non - dominating alternatives (Vallee, 1994). For this purpose, the weights of attributes used in selecting the site, and a decision matrix should be available (Xiaomin et al., 2001). ELECTRE III is based on the comparison of alternatives with respect to their attributes when they are dichotomized into acceptable and not acceptable categories to obtain attribute weights and ma- 
trices $(C(a, b)$ and $D(a, b)$. This will enable one to obtain the data, by using the elimination algorithm, which will help us to make a decision (Roy, 1996; Rogers, Bruen, 2000).

The initial data should describe the alternatives and their attributes. For example, it is necessary to define thresholds for the variation of quantitative values of attributes, which may be divided into 1) indifference threshold $\left.q_{j}(a) ; 2\right)$ preference threshold of $\left.p_{j}(a) ; 3\right)$ veto threshold (VETO) $v_{j}(a)$.

Then a solution based on a standard algorithm is used yielding the preference order for siting a commercial building.

Synthesizing multicriteria decision making techniques for selecting effective design, technological and organizational variants of buildings. A major goal of this approach is to combine a number of the alternatives of analyzed construction processes or projects of a building into an integrated building system. In determining the goals and making designs, efforts are made to avoid the potential errors. A comprehensive analysis of design problems associated with the potential construction work, building materials and equipment to be used, as well as the state of construction market and the related quality control problems allow us to save much time, resources and money.

In the present investigation, algorithms of the methods of synthesis for combining several phases of construction processes or projects into a general system are used as one of the effective tools of integrating multicriteria decision methods into decision support systems. In this respect, the analysis of the problems associated with integrating separate structures into a general system, thereby solving the problems of interconnections of different stage alternatives, is a very important area of multicriteria decision making.

Therefore, further can be applied new multicriteria decision synthesis approaches (Šarka, Zavadskas, Ustinovičius, 2000; Šarka, Ustinovičius, Zavadskas, 1999):

- project synthesis based on compromise compensating model (SKK3);

- project synthesis based on the criterion of success ("wins") (PSS2) of a decision (multicriteria decision synthesis (DSS1);

- project multicriteria decision synthesis based on the average weighted decision success criteria (DSS2).

The structure of DSS1 model. A decision project synthesis based on the success of a decision (PSS2) according to DSS1 approach is made in 3 stages, each of which is further subdivided into minor actions. Stage 1 is aimed at the collection of the initial data and developing a database structure (DBS). Stage 2 of DSS1 method includes intermediate decision making. Here, the alternatives left for further consideration at the particular stage are given and a preliminary preference set of alternatives is formed based on similarity to the ideal solution. Stage 3 is aimed at multiple criteria decision synthesis and the formation of the final preference set of the alternatives synthesized.

Determining the financing strategies. To determine the strategy of financing, a number of qualitative attributes are considered. On the other hand, both qualitative and quantitative attributes have some disadvantages, being differently interpreted in the particular range of the value (Roubens, 1982). Therefore, in this case, it is hardly correct to apply multicriteria approaches. ELECTRE IV technique seems to be most appropriate of all currently used methods to solve the above problem. Major steps of implementing the above technique to formulating and solving the problem are given below (Vallee, 1994).

Collection of the initial data in ELECTRE IV technique. At the first stage, the criteria for efficiency evaluation are formulated and the alternatives are selected.

A set of attributes $(j, \ldots, m)$ is formed by a decision maker, for which the preference thresholds will be modelled later. The attribute $j$ evaluates every action and the related outcome. The action a evaluated by the attribute $j$ is denoted by $g_{j}(a)$. When an attribute $j$ defines two actions $a$ and $b$, then: 
$a P_{j} b \Leftrightarrow g_{j}(a)>g_{j}(b)-a$ has a much higher preference order than $\mathrm{b}$ with respect to the attribute $\mathrm{j}$;

$a I_{j} b \Leftrightarrow g_{j}(a)=g_{j}(b)-a$ is indifferent to $b$ with respect to the attribute $j$.

The second step involves the formation of a decision matrix. A particular way of describing the attribute was chosen and the preference order defined, providing the following information about the attributes: preference order direction; indifference threshold $\left(q_{j}\right)$; preference threshold $\left(p_{j}\right)$; Veto threshold $\left(v_{j}\right)$.

The thresholds are calculated in four various contexts (Rogers, Bruen, 2000), because

- preference thresholds can be increasing or decreasing,

- they can be either direct (calculated for a worse case) or inverse (calculated for a better case).

Hence, four cases are found:

Case 1. Increasing preference $\uparrow$, direct calculation of thresholds $\rightarrow$

Case 2. Decreasing preference $\downarrow$, direct calculation of thresholds $\rightarrow$

Case 3. Increasing preference $\uparrow$, inverse calculation of thresholds $\leftarrow$

Case 4. Decreasing preference $\downarrow$, inverse calculation of thresholds $\leftarrow$

Based on the above assumptions, a set of attributes to be used may be described.

Quantitative attributes. In determining the efficiency of financing strategies the following quantitative attributes were used: equity ratio, lender's capital ratio.

Qualitative attributes. The evaluation of the following subjective or objective criteria is of particular importance: lender's risk, decreasing the payment rate, withdrawal contract, subsidized interest, state financing.

Then the standard algorithm is used in the solution, and the preferences of the financial schemes are established, based on the data obtained.

\section{VERBAL ANALYSIS FOR EVALUATING THE EFFICIENCY OF INVESTMENT PROJECTS}

In this chapter a new method of choosing the best alternative of a fuzzy set, free of the above limitations, is offered. It is developed to evaluate the efficiency of construction investment projects to demonstrate the efficiency of the approach. The problem is formalized and a description of the suggested method is provided in terms of decision making techniques.

Method of Comparison of Alternatives (SNOD) based on construction of the scale of Normalized and Ordered Differences (Larichev, Kochin, Ustinovichius, 2003a,b). The assumptions about the DM judgements used in SNOD are the same as those adopted in PARK technique:

1. The DM is able to compare two alternatives for preference ordering based on multiple efficiency criteria analysis.

2. The DM can compare multicriteria alternatives for preference ordering based on only two criteria of efficiency

The DM can compare two alternatives differing by two criteria for ordering if one alternative is more preferable than the other by one criterion.

In addition, an assumption is made that the set of efficiency criteria can be subdivided into independent subsets. In our case, three subsets of criteria based on price, actual existence and the number of potential purchasers are formed. The criteria belonging to a particular set may be both dependent and independent in terms of preference ordering.

Based on the above assumptions, a comparison of two multicriteria alternatives, when the disadvantages of one are proportional to those of another, is made aimed at determining which of the alternatives has fewer disadvantages and more advantages.

Formal analysis. Computer - aided analysis of the problem does not provide for the DM participation. In this analysis the weights of 
efficiency criteria are assumed to be equal. The analysis is aimed at preparing a set of the questions to be posed to the DM, which would provide:

- the minimum load for the DM and the least number of questions;

- questions of gradually ascending difficulty;

- the highest amount of information received from the DM.

Formal analysis is made at two stages:

Stage 1 is pairwise comparison of the available alternatives. This is a computer - aided analysis based on the following algorithm:

1 . The results of the evaluation are normalized for any pair of the alternatives compared:

a) the mean value is found for the assessments of two alternatives compared in a quantitative scale;

b) assessments in qualitative scales are converted to scores to obtain the "mean" value.

c) if the highest value $(\max )$ is to be obtained by the criterion, the evaluation outcome is divided by the mean value, while if the least value ( $\mathrm{min}$ ) is to be reached, the mean value is divided by the evaluation value.

2 . In this way, the total score of the alternatives is obtained. The alternative with the highest score is the winner.

Stage 2 is also entirely based on computer - aided analysis without the DM participation which is aimed at preparing the questions for getting the DM's preferences. It consists of the following procedures:

a) the alternative with the largest number of "wins" in pairwise comparison is considered the potentially best alternative (PBA):

b) the alternatives not Pareto dominated with respect to PBA are no longer considered;

c) other pairwise compared alternatives are ordered based on the total scoring difference between PBA and the particular alternative, from the highest to the lowest score.

DM/DSS dialogue. The DM preference is received by pairwise comparison of alternatives, beginning with the pairs where the potentially best alternative DBA is relatively better.
The dialogue can be presented as a series of successive steps:

Step 1 - comparison preparation. At this stage, the DM considers the assessments of two alternatives offered to him/her and answers the following questions:

1. Are there any alternative assessments with slight differences which may be considered practically equal by pairwise comparison?

2. Are there any alternatives which can be eliminated from the set considered, because their quality is unacceptable by the criterion available?

Step 2. Normalization of advantages and disadvantages of the alternative pair. After the first screening stage the assessment results of the remained alternatives are normalized. Then the attributes are arranged in the descending order of PBA advantages in the pair.

Then the DM makes pairwise comparison of PBA advantages and disadvantages with respect to another alternative, stating the preference according to his judgements. A scale for ordering relative alternative normalization differences based on the DM preferences is developed.

Step 3. Comparison performed by the DM. At this stage, a set ordered by descending advantages scores and supplemented with an ordered set of disadvantages based on ascending order of scores, is considered. A scale of normalized relative differences makes the basis of the DM questioning. As shown above, the conditions to offset (compensate) PBA disadvantages in pairs (beginning from the greatest one) by the advantages (also beginning from the greatest one) are stated.

Giving instructions and recommendations. In most cases, SNOD technique can be helpful for the DM in choosing the best alternative. However, there are cases where the alternatives turn out to be incomparable. Then the following information is provided to the DM by SNOD method:

- the best alternative with the highest score of normalized evaluations is specified. 
- The DM is informed about another alternative similar to PBA, with the scoring of such alternatives given.

- The DM is prompted to enter some more criteria allowing to identify incomparable alternatives (according to this method).

In this case, the DM is allowed to make the final choice.

Checking the DM preference consistency. The procedure is performed by fixing (checking) all the comparisons made by the DM. In case of multiple alternatives cycles, the DM is prompted to look through pairwise comparisons for identifying the cases to be excluded from the cycle.

\section{GAME THEORIES IN CONSTRUCTION INVESTMENT ANALYSIS}

Mathematical models may be referred to classical optimization or multiple criterion decision problems, depending on major data, constraints or objective function. They can be solved for cases either of definite or indefinite information. According to game theory and under the condition of indefiniteness of the alternative selection the problem may be referred to one of the following types:

a) problems of stochastic indefiniteness arbitrary conditions described in terms of statistical distribution.

b) problems of total indefiniteness - the probability of effects of random action and the environmental factors is unknown. A decision is made by comparing advantages and disadvantages of the potential variant under various environmental conditions.

In completely defined problems unreliability or deviations are not taken into account. The preliminary stated limiting conditions are satisfied by forced decisions, while the unfavourable initial data are corrected based on practical experience. In this way, admissible but often unfavourable decisions are made. The above problems are intended only for a theoretically ideal case.
The characteristics of implemented projects are different from those given in the initial variants. Many problems lack the essential data, while the provided data are incomplete or unreliable. When the uncertainty is caused by random factors defined by various statistical methods based on distribution laws, then we have the problems of stochastic indefiniteness (Zavadskas, Peldschus, Ustinovichius, 2003). When the laws governing the effects of environmental conditions and their probability are unknown, we get the conditions of total indefiniteness. Then decisions are made by considering the advantages and disadvantages of the potential alternatives in the context of varying environmental conditions (Peldschus, 1986). The problems of this type can usually be solved only by game theory approach.

If weights of attributes are unknown in a problem, it should be considered a problem to be solved under the conditions of uncertainty (indefiniteness). In this case, game theory approaches may be applied.

The structure of LEVI 3.0 technique and some methods of solving the problems. The technique and the computer program LEVI 3.0 offer various optimization methods to solving the problem under uncertainty conditions (Peldschus, Messing et al., 2002). Following the instructions given, it is possible to make an optimal choice from a set of available decisions.

LEVI 3.0 is based on the integration of various multicriteria methods. The structure of this approach is shown in Figure 6.

Determining normalization sensitivity. In the context of game theory approaches, the dimensionless attribute efficiency values should be used when solving the construction technology problems. The above values should express the relationship with respect to an optimal value, be independent of the matrix type and remain identical for the same relative difference in maximization and minimization problems.

In the approach described, the appropriate normalization procedures for solving maximization and minimization problems are used: 


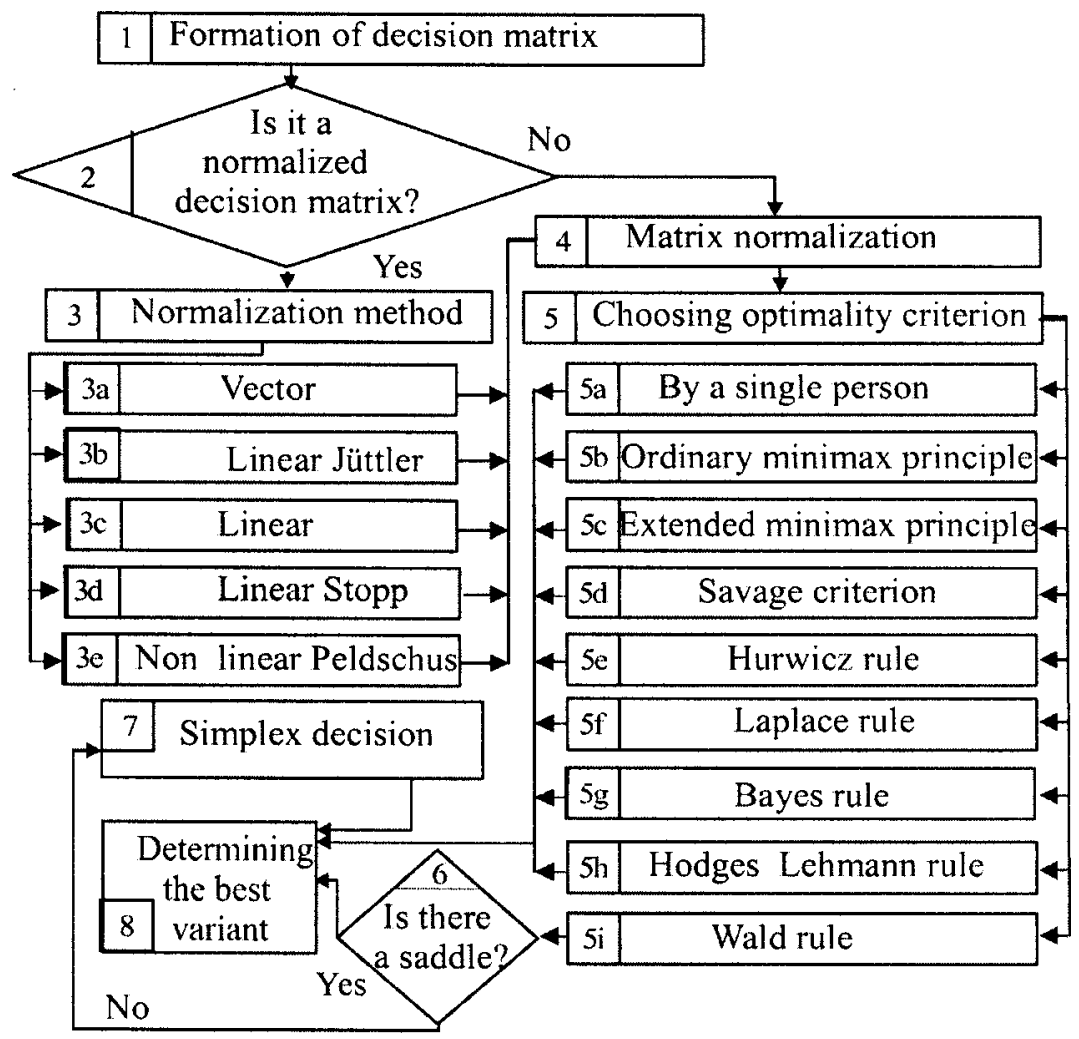

Figure 6. Structural diagram of selection of the best variant under complete indefiniteness (uncertainty) conditions

vector normalization (Hwang, Yoon, 1981), linear normalization (Weitendorf, Körth, Stopp methods) (Weitendorf, 1976; Körth, 1969; Stopp, 1975), non linear normalization (Peldschus method) (Peldschus, 1986).

The particular normalization technique applied may affect decision making to some extent (Peldschus, 2001; Zavadskas, Peldschus, Ustinovichius, 2003). The dimensionless values used in applying matrix game theory to solve the problems of construction investments efficiency should satisfy the following requirements:

- they should express the relationship with an optimal value;

- they should be independent of the type of matrix;

- they should remain unchanged for maximization and minimization under the same per cent changes;

- optimal values can take any place in the matrix.

To meet the above requirements the formulas given below are suggested:

$b_{i j}=\left(\frac{\min _{i} a_{i j}}{a_{i j}}\right)^{3}$, if $\min _{i} a_{i j}$ is favourable
$b_{i j}=\left(\frac{a_{i j}}{\max _{i} a_{i j}}\right)^{2}$, if $\max _{i} a_{i j}$ is favourable

here, a decision matrix is denoted by $a_{i j} ; i=1$, $m ; j=1, n$.

Calculation of efficient strategies. The approach LEVI 3.0 is based on the following decision making principles and rules: simple mini- 
max principle (Manteufel et al., 1977); extended minimax principle (Manteufel et al., 1977); Wald rule (Wald, 1945); Savage rule (Savage, 1951); Hurwicz rule (Hurwicz, 1951); Bernoulli Laplace rule (Bernoulli, 1738); Bayes rule (Arrow, 1949); Hodges - Lehmann rule (Hodges, Lehmann, 1952).

\section{A MATHEMATICAL METHOD OF DETERMINING INVESTMENT EFFICIENCY}

In real estate sector, especially in construction or purchasing of commercial buildings, adequate evaluation of market development and property management is of paramount importance. To ensure the reliability of the investment projects, which is closely associated with the appropriate research into the problems of market and property management and processing of the data obtained, it is necessary to define a set of criteria for the appropriate building selection. A comprehensive analysis of reliable market data is a most important factor for developing the construction investment projects as well as for the selection of property management project and the appropriate processing of attributes by various mathematical models (Ireland et al., 2002; Stasiulionis, Ustinovičius, 2003).

The rent and market price of the premises largely depend on the quality of the particular building. Buildings are divided into three groups (classes) according to construction quality: A, $\mathrm{B}$ and $\mathrm{C}$.

The requirements for office buildings of the class A include air conditioners, modern lifts, large parking area, good communication lines, modern IT means, 24 hour guard, accessibility for transport and good visibility. B class office buildings are of sufficiently high quality, however, they may lack lifts, air conditioners or sufficient parking space. C class offices are of satisfactory quality, being located in old buildings. They often do not meet any of the requirements for A class buildings.

Analysis of office repair, initial pur- chase and sale prices in the city of Vilnius. On the basis of the calculations made, the table and cost graphs were drawn showing the dependence of estimated cost of $1 \mathrm{~m}^{2}$ of total office area on the class of a commercial building (Ustinovichius, Podvezko, 2003). The graph is rather subjective, because cost estimation of building finishing is a complicated problem, associated with individual, often unique features of the particular buildings. Therefore, the costs are estimated in terms of the intervals separating the maximum and minimum costs. Further, cost level in graphs is represented as bars (not lines).

Cost analysis of office buildings. The cost of $1 \mathrm{~m}^{2}$ office area in a repaired building depends on the grade (A, B, C) and largely on its location. The city area may be divided into zones of buildings practically of similar classes. However, there will be some differences between the buildings of the same class, depending on the location of a particular building. This is why costs of office area are represented in terms of intervals (separating the maximum and minimum cost prices).

Initial price of purchasing non - repaired offices. The price of such offices depends primarily on their location. A division of the city areas is similar to that used for sale price analysis.

Fundamental principles of mathematical modelling. Mathematical modelling can be used for determining the efficiency of the investment projects. A mathematical method offered by the author for evaluating the efficiency of investment in the commercial building purchase, repair and sale is given below. In developing this method much attention is paid to the accuracy of the initial data and investment risk analysis. Notations: $\mathrm{k}$ - class of building; $k=1,2,3 \quad(k \in N) ; r$ - district No; $P(k)$ - building sale price; $P_{\min }(k), P_{\max }(k)-$ minimum and maximum price; $R_{\text {min }}(k)$, $R_{\text {max }}(k)$ - minimum and maximum repair cost (the initial purchase cost included); $\bar{P}(k), \bar{R}(k)$ - average prices, respectively.

Based on the statistical data $P_{\text {min }}(k)$, 
$P_{\text {max }}(k), R_{\text {min }}(k), R_{\text {max }}(k)$, where $k=k_{\text {min }}$, $k_{\text {min }}+1, \ldots, k_{\text {max }}$ (in our case, $k=1,2,3$ ) interpolation polynomials of $n=k_{\max }-k_{\text {min }}$ degree (in our case, second order parabole $n=3-1=2$ ), are obtained, which are written as $a_{n} k^{n}+a_{n-1} k^{n-1}+\ldots+a_{1} k+a_{0}$ for all dependent $\mathrm{P}_{\text {min }}(\mathrm{k}), \quad \mathrm{P}_{\text {max }}(\mathrm{k}), \quad \bar{P}(k), \bar{R}(k), \mathrm{R}_{\text {min }}(\mathrm{k})$, $\mathrm{R}_{\text {max }}(\mathrm{k})$, where variable $\mathrm{k}$ is changing continuously, rather than discretely: $k_{\min } \leq k \leq k_{\max }$. This set is denoted by $K$.

Determining zones of various investment risk exposure. Risk zones may be defined as risk free, normal risk, high risk zones and a zone of losses. Their detailed analysis is given below.

Risk - free zone of investment. This is an area where the minimum sale price of premises $P_{\text {min }}(k)$ is higher than the maximum price of repaired building $R_{\text {max }}(k)$ (initial purchase price included), i.e. a set $k$ of values $K_{+}$satisfying this inequality, $P_{\min }(k)-R_{\max } k>0$.This set may be empty $\varnothing$ or representing a combination of separate interval sections from $k \in\left[k_{\min }, k_{\max }\right]$.

Normal risk zone of investment $K_{=}$. This is zone $\bar{K}$, where average sale price $\bar{P}(k)$ is higher than average repair price $\bar{R}(k)$ (initial purchase cost included), except for risk - free investment zone $K_{+}: K_{=}=\bar{K} \backslash K_{+}$.

High risk investment zone $K_{0}$ and zone of losses $K_{-}$. These two zones may be defined simultaneously, or $K_{0}$ may be determined after $K_{-}$.

Zone of investment losses $K_{-}$(if any) is a zone where the maximum sale price of premises $P_{\text {max }}(k)$ is lower than the minimum repair cost (primary purchase price included) $R_{\text {min }}$.

Mathematical model of cost analysis of office repair, purchase and sale in Vilnius. Based on a correlation analysis of the data, major relationships were determined, which make a model for determining the value of repair purchase and sale of Vilnius office buildings.

Models for determining risk zones of investment in office buildings. A set of relationships obtained can be used for developing mathematical models for determining various types of investment risk zones (Table 1).

By applying the defined mathematical models, the graphs of distribution of various investment risk zones in Vilnius districts were plotted (graphs of individual districts are shown in (Ustinovichius, Podvezko, 2003).

\section{CONCLUSIONS}

1. A complex analysis of methods and techniques currently used by the researchers of various countries to determine the efficiency of investments was made. It was found that currently used methods have not a few drawbacks, therefore, their application can result in lower construction investment efficiency.

Table 1. Models for determining risk zones

\begin{tabular}{lll}
\hline No. & Model application & Model expression \\
\hline 1 & Risk - free investment & $P_{\min }(k)-R_{\max } k \neq-1265,5+635,6 k+596,37 r-77,86 k^{2}-$ \\
& & $-82,18 r^{2}+10,096 k^{3}+4,3658 r^{3}$ \\
\hline 2 & Nones & $\bar{P}(k)-\bar{R}(k)=-734,44+553,04 k+721,84 r-291,49 k^{2}-$ \\
& & $-105,94 r^{2}+5,418 k^{3}+5,6829 r^{3}$ \\
\hline 3 & High risk and losses zones & $R_{\min }(k)-P_{\max } k \neq 836,13-788,28 k-847,3 r+544,05 k^{2}+$ \\
& & $+129,7 r^{2}-0,74 k^{3}-7 r^{3}$ \\
\hline
\end{tabular}


Advantages and disadvantages of commonly used decision making methods were described and it was stated that the particular features of the above techniques should be assessed by applying them to actual problems of decision making. It was found that verbal methods could be most advantageously used for evaluating the efficiency of construction investments.

2 . A classification of the construction investment projects and problems aimed at determining their efficiency was made. The subgroups of buildings allowing for the application of similar criteria for efficiency evaluation and preference ordering were determined. The stages of efficiency evaluation of construction investments were outlined. The overall efficiency of construction investments projects was determined on the basis of the efficiency evaluation results obtained at every stage.

3. A family of MADM methods to solve the problems of evaluating the efficiency of construction and reconstruction investment projects was created. The new developments include:

- A quantitative multicriteria approach MKDM1 to be used for determining investment efficiency based on precisely defined quantitative attributes was developed. A technique for determining aggregate weights of attributes was created within this approach. It can be used when a considerable difference between objective and subjective weights of attributes is observed. A method of pairwise comparison expertise for determining the preference of attribute weights was refined. This method provides an additional means of checking the concordance of experts' judgements and the reliability of their evaluation. The iterative multicriteria decision approach suggested by the author yields more precise multicriteria evaluation, as well as providing generalized description of the results obtained by decision making methods and drawing the conclusions.
- ELECTRE III and ELECTRE IV techniques were implemented. They can be used to evaluate the efficiency of construction investment problems when the quantitative and qualitative criteria are described in terms of thresholds (preference, indifference and veto thresholds). It was found that ELECTRE IV technique based on a set of dominated criteria is most efficient in evaluating the financing startegies in construction. In determining the siting strategy for commercial buildings a decision making technique ELECTRE III was found to be more efficient.

- A verbal approach SNOD (Scale of Normalized and Ordered Differences) was developed for determining the efficiency of construction and reconstruction projects. From psychological perspective, SNOD applies rather simple preference ordering procedures. The dialogue is based on every - day language familiar to the decision maker. Quantitative and qualitative criteria are used in the framework of this approach.

- A newly developed method LEVI 3.0 is based on a set of game theory principles (optimization criteria). The application of the suggested technique results in more reliable decision making.

4. A mathematical model to determine the efficiency of investment in commercial buildings (for purchasing, sale and repairs) was developed. Based on this model, the expected profit and risks of the project may be assessed. Initial data are given and analysed in terms of minimum and maximum intervals of values. This approach allows us to increase the accuracy of the results obtained and to evaluate project risks based on the developed risk zones classification determining the extent of risk exposure of the project considered.

5. Multicriteria decision support system to solve construction investment problems, allowing the comprehensive analysis of construction investment efficiency to be made is created. 
The system includes a set of multicriteria decision methods, a mathematical model for evaluating construction investments and a synthesis method DSS1 created by the author for selecting efficient building design, technological and organization projects.

- A synthesis approach DSS1 to select optimal design, technological and organizational projects, providing the user with a set of preference orders of synthesized variants, was developed.

\section{REFERENCES}

Arrow, K. J. (1949) Bayes and Minimax Solutions of Sequential Decision Problems. Econometrica, p. 213-243.

Arditi, D., Gunaydin, H. M. (1998) Perception of process quality in building projects. Journal of Management in Engineering, 15(2), p. 43-53.

Behrens, W., Hawranek, P. M. (1991) Manual for the Preparation of Industrial Feasibility Studies. Vienna: UNIDO Publication, 385 p.

Bernouli, D. (1738) New theoretical example of occurrence of value. Comentarii Academiae Scientarium Inperialis Petropolitanae, p. 175-192. (In French).

Bloech, J., Götze, U., Huch, B., Lücke, W., Rudolph, F. (1994) Strategic planning. Tools, samples of action of information systems. Heidelberg. (In German).

Blohm, H., Lüder, K. (1991) Weak establishments in the field of industrial investments and ways of their elimination, 7 Edition, Munich. (In German).

Brown, G. (1991) Property Investment and the Capital Markets. Spon, London.

Busse von Colbe, W., Laßmann, G. (1990) The theory of a factory facilities, that 3: the theory of the investment, 3 Edition, Berlin, Heidelberg. (In German).

Chu, A. T. W., Kalaba, R. E., Spingarn, K. (1979) A comparison of two methods for determining the weights of belonging to fuzzy sets. Journal of Optimization Theory and Application, 27, p. 531-538.

Cook, W. D., Kress, M. (1994) A multiple-criteria composite index model for quantitative and qualitative data. European Journal of Operational Research, 78, p. 367-379.

Eilenberg G. (1991). Industrial financial facilities,
4 Edition, Munich, Vienna. (in German).

Environmental Systems Research Institute. (2001). ARC/INFO The Professional Geographic Information System. The United States.

Evlanov L. G. (1984). Theory and practice a decision making. Moscow: Ekonomica, 176 p. (in Russian).

Fan Z. (1994). A new method for multiple attribute decision making. Systems Engineering, 12, 2528.

Fandel G. (1979). Acceptance of the optimum decision in the organizations, Berlin, Heidelberg, New York. (in German).

French N., French S. (1997). Decision theory and real estate investment. Journal of Property Valuation \& Investment, Vol 15, No. 3, 226-232.

Friedman J. P., Ordway N. (1997) Income Property Appraisal and Analysis. Prentice Hall Englewood Cliffs, New Jersey, $461 \mathrm{p}$.

Ghasemzadeh F., Archer N. P. (2000). Project Portfolio selection through decision support. Decision Support Systems, Vol 29, No 1, 73-89.

Heinhold M. (1997). The preliminary estimate and the account of profits and losses in examples. Schäfer-Poeschel publishing house, Stuttgart. (in German).

Hodges J. L., Lehmann E. L. (1952). The Use of Previous Experience in Reaching Statistical Decision. Annals of Mathematics Studies, 396407.

ter Horst K. W. (1980). Planning of the investment. Stuttgart, Berlin. (in German).

Huch B. (1986). The introduction in preliminary estimate, 8 Edition, Heidelberg. (in German).

Hurwicz L. (1951). Optimality Criteria for Decision Making under Ignorance. Cowles Commission Paper, Statistics, No 370, p. 45-52.

Hwang C. L., Yoon K. (1981). Multiple Attribute Decision Making - Methods and Applications. A State-of-the-Art Surwey, Springer Verlag, Berlin.

Hwang C. L., Lin M. J. (1987). Group Decision Making under Multiple Criteria: Methods and Applications. Springer-Verlag.

Yan J. B., Singh M. G. (1994). An evidential reasoning approach for multiple-attribute decision making with uncertainty. IEEE Transactions on Systems, Man and Cybernetics, 24, 1-18.

Ireland M. W., O‘Connor P. M. (2002). Location Analysis for Commercial Properties Assessment Journal, Vol. 9, No 6, 21-27.

Jones C. (1990). Investments - Analysis and Manggement. John Wiley \& Sons, Chichester. 
Keeney R. L., Raiffa H. (1976). Decisions With Multiple Objectives: Preference and Value Tradeoffs. Wiley, New York.

Kern W. (1976). The basic features of the investment. Stuttgart. (in German).

Kilger W. (1986). The introduction in preliminary estimate, 3 Edition, Wiesbaden. (in German).

Körth H. (1969). The account of the big criterion functions by optimization of manufacture of a canvas. Mathematik und Wirtschaft (Mathematics and facilities), that 6, Berlin: Verlag die Wirtschaft, 184-201. (in German).

Kruschwitz L. (2000) Estimation of the investment, 8 Editions, Oldenbourg, Munich, Vienna. (in German).

Larichev O. I., Brown R. V. (2000). Numerical and Verbal Decision Analysis: Comparison on Practical Cases. Journal of Multi-Criteria Decision Analysis, Vol 9, No 6, 263-274.

Larichev O. I., Kochin D. Yu., Kortnev. A. V. (2002). Decision support system for classification of a finite set of multicriteria alternatives. Decision Support Systems, Vol 33, No 1, 13-21.

Larichev O. I., Olson D. L. (2001). Qualitative methods of decision making. Kluwer Academic Publishers.

Larichev O., Kochin D., Ustinovichius L. (2003a). Multicriteria method of choosing the best alternative for investments. In book: DSS in the Uncertainty of the Internet Age. Edited by T.Buy, H.Sroka \& others, Katowice, 255-270.

Larichev O., Kochin D., Ustinovichius L. (2003b). Multicriteria method of choosing the best alternative for investments. International Journal of Strategic Property Management, Vol 7, No 1, 33-43.

Larichev O., Moshkovich H. (1997). Verbal Decision Analysis For Unstructured Problems. Boston, Kluwer Academic Publishers.

Liang G.S., Wang M.J. (1994). Personnel selection using fuzzy MCDM algorithm. European Journal of Operational Research, 78, 22-33.

Lücke W. (1991). The dictionary of the investment. 2 Edition, Munich. (in German).

Lumby S. (1994). Investment Appraisal and Financial Decisions. England, 340p.

Lunkevichius S., Ustinovichius L., Zavadskas E. K., (2001). Substantiation of financing approach for rural property. Statyba (Journal of Civil Engineering and Management), Vol 7, No 2, 148 $-157$.

MacCrimmon K. R. (1968). Decision Marking Among Multiple - Attribute Alternatives: A Survey and Consolidated Approach, RAND
Memorandum, RM-4823-ARPA.

Makridakis S., Wheelright S. C., McGee V. E. (1983). Forecasting: methods and application. 2. ed. New York, John Wiley, 923 p.

Manteufel K., Stumpe D. (1977). The games theory. Mathematics for engineers, natural scientists, economists and farmers. that 21/1. Leipzig: G. Teubner publishing house. (in German).

Nemec E., Breit J., Frick W., Geyer A., Heinhold M., Moser R. Topritzhofer E. (1990). The investment and financing, in: to social study about the organization of manufacture texts for the basic study, Hg. Fritz Scheuch branch publishing house. (in German).

Pekelman D., Sen S. K. (1974). Mathematical programing models for the determination of attribute weights. Management Science, 20, 1217-1229.

Peldschus F. (1986). Application of the games theory for problems of building technology. Dissertation B, Leipzig TH, 119 p.

Peldschus F. (2001). Research on the sensitivity of the multicriterion evaluation methods. Statyba (Journal of Civil Engineering and Management), Vol 7, No 4, 276-281. (in German).

Peldschus F., Messing D., Zavadskas E. K., Ustinovichius L. (2002). LEVI 3.0 - Multiple Criteria Evaluation Program. Journal of Civil Engineering and Management, Vol 7, No 3, 184191.

Perridon L., Steiner M. (1999). Financial economy of the enterprise, 10 Edition, Munich. (in German).

Riedel H. (1989). The system analysis of profitability: processes and tools to the monetary quotation of investments within the framework of computer integrated manufacturing strategy. The dissertation, Goettingen. (in German).

Rogers M., Bruen M. (2000). Using ELECTRE III to Choose Route for Dublin Port Motorway. Journal of Transportation Engineering, Vol 126, No 4, 313-324.

Roy B. (1996). Multicriteria Methodology for Decision Aiding. Kluwer Academic Publishers, Dortrecht, 293 p.

Roubens M. (1982). Preference relations on actions and criteria in multicriteria decision making. European Journal of Operational Research, 10, 51-55.

Saaty T. L. (1994). Fundamentals of Decision Making and Priority Theory with the AHP. RWS Publications, Pittsburgh, PA, USA.

Savage L. J. (1951). The Theory of Statistical Decision. Journal of the American Statistical 
Association, 55-57.

Schulte K. W. (1986). The analysis of profitability. 4 Edition, Heidelberg, Vienna. (in German).

Srinivasan V., Shocker A. D. (1973). Linear programming techniques for multidimensional analysis of priviledged", Psychometrika, 38, 337-369.

Stasiulionis A., Ustinovichius L. (2003). The analysis and evaluation of investment variants in commercial real estate. Technological And Economic Development Of Economy, Vol 9, No 3, 105-115. (in Lithuanian).

Stopp F. (1975). Comparison of variants by matrix games. Wissenschaftliche Zeitschrift der Hochschule für Bauwesen Leipzig (Scientific magazine of institute for a building affair Leipzig), the brochure 2, $185 \mathrm{p}$. (in German).

Šarka V., Ustinovičius L., Zavadskas E. K. (1999). Project synthesis using compromisecompensating model in decision support system in construction industry. Statyba (Journal of Civil Engineering and Management), Vol 5, No 6, 374-385. (in Lithuanian).

Šarka V., Zavadskas E. K., Ustinovičius L. (2000). Method of project multicriteria decision synthesis on the basis of decision success criterion. Statyba (Journal of Civil Engineering and Management), Vol 7, No 3, 193-201. (in Lithuanian).

Tarasevich J. I. (2000). The analysis of real estate investments. St. Petersburg: MKS. (in Russian).

Triantaphyllou E. (2000). Multi-criteria decision making methods a comparative study. Kluwer Academic Publishers, Boston.

Ustinovichius L. (2001a). Determining integrated weights of attributes. Statyba (Journal of Civil Engineering and Management), Vol 7, No 4, 321326.

Ustinovichius L. (2001b). Multi-criteria analysis of the efficiency of construction investments. Almanach des praktischen Managements in Mittel-und Ost-Europa, Band Nr.3, Nordic Academy of Informatization e. V. i. G. Mit Sitz in Stralsund, 107-114.

Ustinovichius L., Jakuchionis S. (2000). Multicriteria analysis of the variants of the old town building renovation in the marketing aspect. Statyba (Journal of Civil Engineering and Management), Vol 6, No 6, 469-475.
Ustinovichius L., Podvezko V. (2003). A mathematical modelling method of determing investment efficiency in construction. Modelling and Simulation of Buisness Systems. Proceedings of the International Conference held in Kaunas, Lithuania 13-14th May 2003. ISBN 9955-09-420-6, 160 - 164.

Ustinovičius L., Stasiulionis A. (2001). Multicriteria-based estimation of selection of commercial property construction site. Statyba (Journal of Civil Engineering and Management), Vol 7, No 6, 474-480. (in Lithuanian).

Vallee D. (1994). Electre III-IV, the version 3.x Aspects of methodology (that 1). University of Paris Dauphine, 53 p. (in French).

Vetschera R. (1991). Support group decision systems: for dialogue in education, Heidelberg. (in German).

Wald A. (1945). Statistical decisions functions which minimise the maximum risk. Annals of Mathematics, 265-280.

Weber H. K. (1991). Productive and economic book keeping. that 2: costs and productivity, 3 Editions, Munich. (in German).

Weitendorf D. (1976). Paper for optimisation of buildings spatial structure. Dissertation A, institute of architecture and construction. Weimar. (in German).

Xiaomin M. Wang, Zhilin L. Qin, An D. Hu Yuda. (2001). Interactive Algotithm for Multicriteria Decision Making: The Attainable Reference Point Method. IEEE Transactions on Systems, Man \& Cybernetics. Part A, Vol 31, No 3, 194199.

Zadeh L. A. (1978). Fuzzy Sets as a Basis for a Theory of Possibility. Fuzzy Sets and Systems, No $1,3-28$.

Zavadskas E. K., Peldschus F., Kaklauskas A. (1995). Multiple criteria evaluation of projects in construction. Vilnius: Technika.

Zavadskas E. K., Peldschus F., Ustinovichius L. (2003). Development of software for multiple criteria evaluation. Informatica, Vol. 14, No 2, 259-272. 